\title{
Evaluation of Morphologic and Morphometric Characteristic of Foramen Transversarium on 3-Dimensional Multidetector Computed Tomography Angiography
}

\author{
Ayfer METIN TELLIOGLU1', Yasemin DURUM², Mustafa GOK², Ayse Gizem POLAT ${ }^{1}$, Can Zafer KARAMAN², \\ Sacide KARAKAS ${ }^{1}$
}

${ }^{1}$ Adnan Menderes University, Faculty of Medicine, Department of Anatomy, Aydin, Turkey

${ }^{2}$ Adnan Menderes University, Faculty of Medicine, Department of Radiology, Aydin, Turkey

This study was presented at the XXIV International Symposium on Morphological Sciences in 02- 06 September, 2015, Istanbul, Turkey.

\section{ABSTRACT}

AIM: To investigate the size and variations of the foramen transversarium (TF). In addition, to study the anatomical variations of the vertebral artery entering the transverse foramen of the cervical vertebrae.

MATERIAL and METHODS: The images of 141 (90 males, 51 females) patients aged 18-79 years (mean: 52.7 years) were analyzed. As a result, 987 cervical spines (C1-C7) and 1974 foramina transversaria were individually evaluated. Each TF's anterior-posterior (AP) and transverse diameter (T) was measured bilaterally from multidetector computed tomography (CT) images. The absence of TF was considered as agenesis and a diameter of less than $2 \mathrm{~mm}$ as hypoplastic. Double foramina and incomplete double foramina were also noted. We evaluated the levels at which the vertebral arteries entered the transverse foramina.

RESULTS: The most frequent variation was duplication of TF, which was noted in a total of 88 (8.91\%) cervical vertebrae. Agenesis of TF was seen in 37 (3.74\%), and hypoplasia of TF in $26(2.63 \%)$ cervical vertebrae. The vertebral artery entered into the transverse foramen of the $5^{\text {th }}$ cervical vertebra from both sides in $4(1.84 \%)$ patients. The vertebral artery entered into the transverse foramen of the $7^{\text {th }}$ cervical vertebra in $4(1.84 \%)$ patients. The vertebral artery entered into the transverse foramen of the $4^{\text {th }}$ cervical vertebra in only $1(0.45 \%)$ patient.

CONCLUSION: We believe that the determination of foraminal variations could be an important guide for neurosurgeons and radiologists in the diagnosis and treatment of diseases in this area.

KEYWORDS: Anatomic variation, Cervical spine, Foramen transversarium, Radiological imaging

\section{INTRODUCTION}

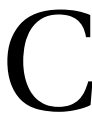
ervical vertebrae are the smallest true vertebrae. The first, second, and seventh cervical vertebrae are unique, cervical vertebrae have a foramen in the transverse process (formerly called the foramen transversarium) (9). The foramen transversarium, which can be found in the first six vertebrae, transmits the vertebral artery and vein accompanied by a plexus of sympathetic nerves. Vertebral arteries in those foramina pass upward to the posterior part of the brain $(5,17)$.

The vertebral artery (VA) is very important for the development of the transverse foramen (TF). The foramina in $\mathrm{C} 7$ are smaller than those in other cervical vertebrae; occasionally these foramina can be absent. The vertebral arteries pass through the TF, except those in $\mathrm{C} 7$ which transmit only small accessory vertebral veins (10). 
Deformities and anatomic variations of the foramina affect the course of vital arteries and nerves, which may cause various clinically pathological symptoms. We think that having good knowledge of the anatomy and variations of bone structures will benefit clinical diagnosis and treatment of diseases in this area. Accordingly, we aimed make a detailed examination of the morphometric and morphologic features and variations of TF using 3-dimensional (3D) multidetector computed tomographic angiography (MDCTA), and to determine the entrance level of the arteria vertebralis to the foramen.

\section{MATERIAL and METHODS}

The study protocol was approved by the Human Ethics Committee of Adnan Menderes University, Turkey. Data were collected from patients, who were referred to the radiology department between January 2014, and January 2015. Images were evaluated retrospectively. Demographic information regarding the patients (age, sex, diagnosis) was assessed from their medical files. Patients who were asymptomatic in the head and neck region were included in the study. Patients with neurological deficits and a history of brain hemorrhage and skull fracture or bone degeneration in the neck region were excluded from the study. No extra imaging for these patients was performed. A 128 detector 160 slice computed tomography (CT) System (Aquilion Prime, Toshiba Medical Systems, Otawara, Japan) was used, and images were transferred to a work station with a direct connection to the CT console. CT examinations of all chosen subjects were performed with high-resolution parameters (80x0.5 $\mathrm{mm}$ detector collimation, $1 \mathrm{~mm}$ slice section thickness, $120 \mathrm{kV})$; therefore, they were suitable for excellent volume rendering (VR) and multiplanar reformation (MPR) processes. We assessed non-contrast and contrast CT images. The assessment of vertebral arteries was only performed with 218 contrasted images. A total of 141 (90 males, 51 females) patients aged 18-79 years (mean: 52.7 years) were analyzed.

As a result, 987 cervical vertebrae (C1-C7) and 1974 TF were individually examined. Each foramen transversarium's anterior-posterior (AP) and transverse diameter was measured bilaterally (Figure 1). The absence of TF was considered as "agenesis", and if the TF diameter was smaller than $2 \mathrm{~mm}$, it was considered as "hypoplasia". Presence of double TF split with a bone lamella was evaluated as "complete duplication". Double TFs that were not split with a bone lamella were evaluated as "incomplete duplication". Angiographic images with contrast were assessed to determine the entrance level of vertebral arteries to the foramen. All data were collected in the Statistical Package for the Social Sciences (SPSS) programme and descriptive statistics are given as tables. Differences between results in terms of right and left side groups were evaluated using Student's t-test and are expressed as means and standard deviation. Statistical significance was accepted as $\mathrm{p}<0.01$.

\section{RESULTS}

A total of 141 (90 males, 51 females) patients, 987 cervical vertebrae (C1-C7), and 1974 units of TF were individually evaluated. Table I shows the AP and transverse diameters of the cervical vertebrae from both sides of $\mathrm{C} 1$ to $\mathrm{C} 7$. In all vertebrae except the $\mathrm{C} 1$ and $\mathrm{C} 7$ vertebrae, the transverse diameters of the TFs were larger than the AP diameter. Both diameters decreased from $\mathrm{C} 1$ to $\mathrm{C} 7$. There was no significant difference between the left and right sides ( $p>0.01$ ) (Table I).

The most frequent variation was the duplication of TF, which was noted in $88(8.91 \%)$ cervical vertebrae in total; 36/88 (41\%) were complete and 52/88 (59\%) were incomplete duplications (Figures 2, 3). C5 was the most common level for duplication (17 complete and 24 incomplete), and the least common level for this variation was C2 (1 complete and 1 incomplete). No duplications were seen at the C1 level. Agenesia of TF was seen in $37 / 987$ (3.74\%) (Figure 4). No agenesia was seen until level C6. Thirty-four cases of agenesia were found at the C6 level and 3 at the $\mathrm{C} 7$ level.

Hypoplasia of TF was seen in 26/987 (2.63\%) cervical vertebrae (Figure 5). It was not observed in the $\mathrm{C} 1, \mathrm{C} 3$, and C5 vertebrae. Hypoplasia was found at C2 $(n=1), C 4(n=1), C 6$ $(n=3)$, and C7 $(n=20)$. Agenesia was observed most frequently at the $\mathrm{C} 7$ level (Table II).

In the present study, the vertebral artery in 4 (1.84\%) patients entered the transverse foramen of the $5^{\text {th }}$ cervical vertebra

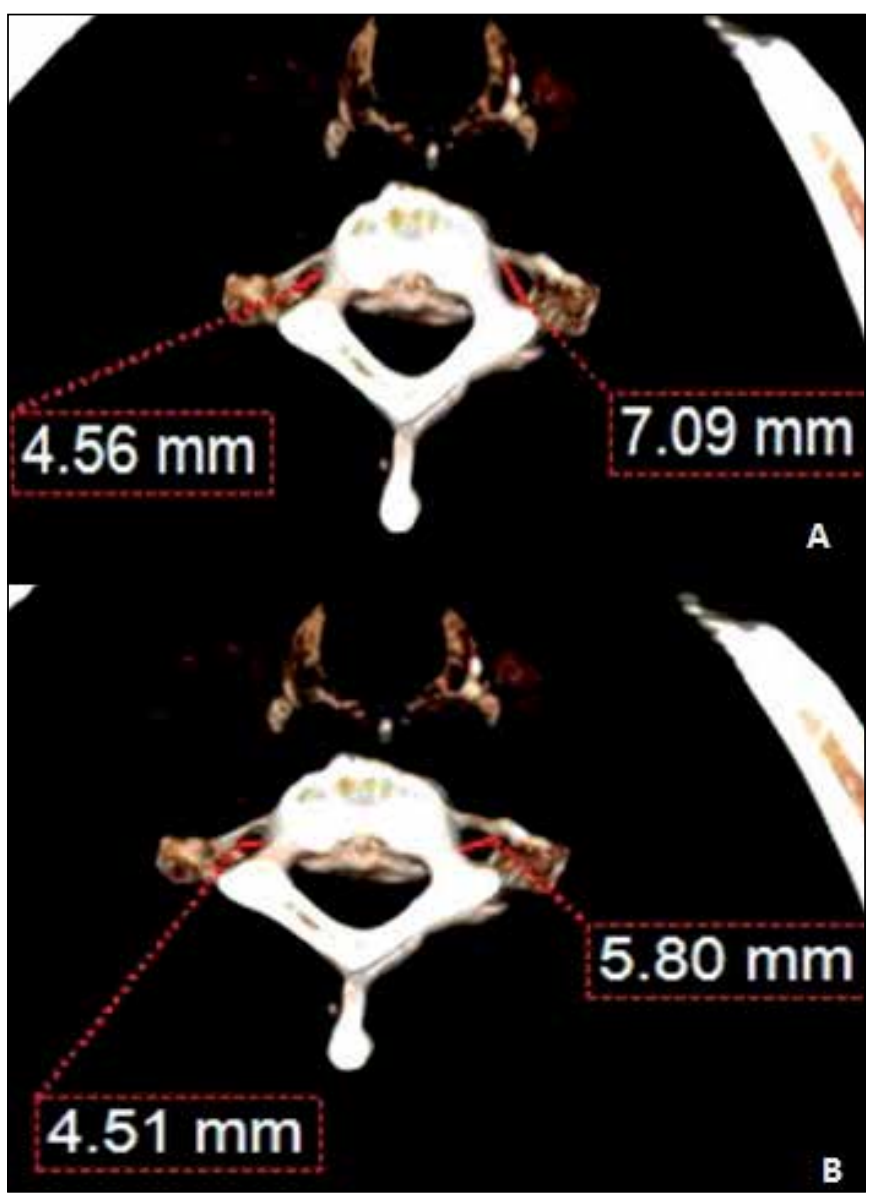

Figure 1: Foramen transversarium's anterior-posterior (AP) " $A$ " and "B" transverse diameters in 3D VR images. 
from both sides (Figure 6A). The vertebral artery entered the transverse foramen of the $7^{\text {th }}$ cervical vertebra in $4(1.84 \%)$ patients. The vertebral artery entered the transverse foramen of the $4^{\text {th }}$ cervical vertebra in only $1(0.45 \%)$ patient. The $6^{\text {th }}$ cervical vertebra was the most common site of entry. The vertebral artery entered the transverse foramen of the $6^{\text {th }}$ cervical vertebra in the remaining 209 (95.87\%) patients (Table III, Figure 6B).

\section{DISCUSSION}

Previous studies on this subject in the literature have mostly been performed on dry bones $(1,3,11,12,14)$. In these studies, only double or triple variations of TF were investigated.
The level of variation, sex, and age affect the results of these kinds of studies. Rathnakar et al. reported a $5.7 \%$ rate of accessory foramen in their dried bone study (12). Chaudhari et al. reported a $23.15 \%$ rate of double foramina in TF (3). Rekha et al. reported double foramina in $6.54 \%$ of $\mathrm{C} 1$ vertebrae (14). Murlimanju et al. reported a $1.6 \%$ rate of foramina accessoria in the cervical vertebra, $5(1.4 \%)$ of which had double foramina and $1(0.3 \%)$ had triple foramina (11). Aggarwal and Gupta examined variations of foramen transversarium in $\mathrm{C7}$ vertebrae (1).

In our study, we evaluated each cervical vertebra (987 cervical vertebrae and $1974 \mathrm{TF}$ ) one by one using 3D CT images. Demographic information of the patients was recorded from

Table I: Definitive Statistics of the Transverse Foramina in both Sides of the C1-C7 Levels of Cervical Vertebrae

\begin{tabular}{|c|c|c|c|c|c|c|}
\hline \multirow{2}{*}{\multicolumn{2}{|c|}{ Diameters (mm) }} & \multicolumn{2}{|c|}{ Right } & \multicolumn{3}{|c|}{ Left } \\
\hline & & \multirow{2}{*}{$\begin{array}{c}\text { Range } \\
6.73 \pm 1.16 \\
6.56 \pm 1.02\end{array}$} & \multirow{2}{*}{$\begin{array}{c}\text { Mean } \pm \text { SD } \\
3.44-11.16 \\
3.71-9.57\end{array}$} & \multirow{2}{*}{$\begin{array}{c}\text { Range } \\
6.70 \pm 1.18 \\
6.62 \pm 0.96\end{array}$} & \multirow{2}{*}{$\begin{array}{c}\text { Mean } \pm \text { SD } \\
3.53-11.86 \\
4.39-9.26\end{array}$} & \multirow{2}{*}{$\begin{array}{c}\mathbf{p} \\
>0.001 \\
>0.001\end{array}$} \\
\hline C1 & $\begin{array}{l}\text { A-P } \\
\text { Transverse }\end{array}$ & & & & & \\
\hline C2 & $\begin{array}{l}\text { A-P } \\
\text { Transverse }\end{array}$ & $\begin{array}{l}5.37 \pm 1.21 \\
6.85 \pm 1.32\end{array}$ & $\begin{array}{c}2.14-8.94 \\
2.01-10.68\end{array}$ & $\begin{array}{l}5.58 \pm 1.16 \\
6.80 \pm 1.50\end{array}$ & $\begin{array}{c}3.84-9.75 \\
3.45-11.50\end{array}$ & $\begin{array}{l}>0.001 \\
>0.001\end{array}$ \\
\hline C3 & $\begin{array}{l}\text { A-P } \\
\text { Transverse }\end{array}$ & $\begin{array}{l}4.50 \pm 0.64 \\
5.86 \pm 1.01\end{array}$ & $\begin{array}{c}2.49-6.47 \\
2.57-12.26\end{array}$ & $\begin{array}{l}4.64 \pm 0.77 \\
5.93 \pm 1.00\end{array}$ & $\begin{array}{l}2.65-7.85 \\
3.28-9.95\end{array}$ & $\begin{array}{l}>0.001 \\
>0.001\end{array}$ \\
\hline C4 & $\begin{array}{l}\text { A-P } \\
\text { Transverse }\end{array}$ & $\begin{array}{l}4.58 \pm 0.85 \\
5.59 \pm 0.94\end{array}$ & $\begin{array}{l}2.55-7.82 \\
3.11-8.60\end{array}$ & $\begin{array}{l}4.74 \pm 0.79 \\
5.67 \pm 0.79\end{array}$ & $\begin{array}{l}2.28-7.56 \\
3.49-7.80\end{array}$ & $\begin{array}{l}>0.001 \\
>0.001\end{array}$ \\
\hline C5 & $\begin{array}{l}\text { A-P } \\
\text { Transverse }\end{array}$ & $\begin{array}{l}4.90 \pm 1.05 \\
5.50 \pm 0.94\end{array}$ & $\begin{array}{l}2.62-8.23 \\
3.39-8.07\end{array}$ & $\begin{array}{l}5.05 \pm 1.00 \\
5.40 \pm 0.97\end{array}$ & $\begin{array}{l}1.77-7.57 \\
2.37-7.60\end{array}$ & $\begin{array}{l}>0.001 \\
>0.001\end{array}$ \\
\hline C6 & $\begin{array}{l}\text { A-P } \\
\text { Transverse }\end{array}$ & $\begin{array}{l}5.18 \pm 1.25 \\
5.37 \pm 1.23\end{array}$ & $\begin{array}{l}2.18-9.11 \\
2.35-9.66\end{array}$ & $\begin{array}{l}5.28 \pm 1.27 \\
5.49 \pm 1.20\end{array}$ & $\begin{array}{c}2.39-10.22 \\
1.87-9.65\end{array}$ & $\begin{array}{l}>0.001 \\
>0.001\end{array}$ \\
\hline C7 & $\begin{array}{l}\text { A-P } \\
\text { Transverse }\end{array}$ & $\begin{array}{l}3.94 \pm 1.57 \\
3.58 \pm 1.25\end{array}$ & $\begin{array}{c}1.07-12.30 \\
1.02-6.83\end{array}$ & $\begin{array}{l}3.80 \pm 1.24 \\
3.60 \pm 1.32\end{array}$ & $\begin{array}{l}1.45-7.45 \\
1.13-8.39\end{array}$ & $\begin{array}{l}>0.001 \\
>0.001\end{array}$ \\
\hline
\end{tabular}

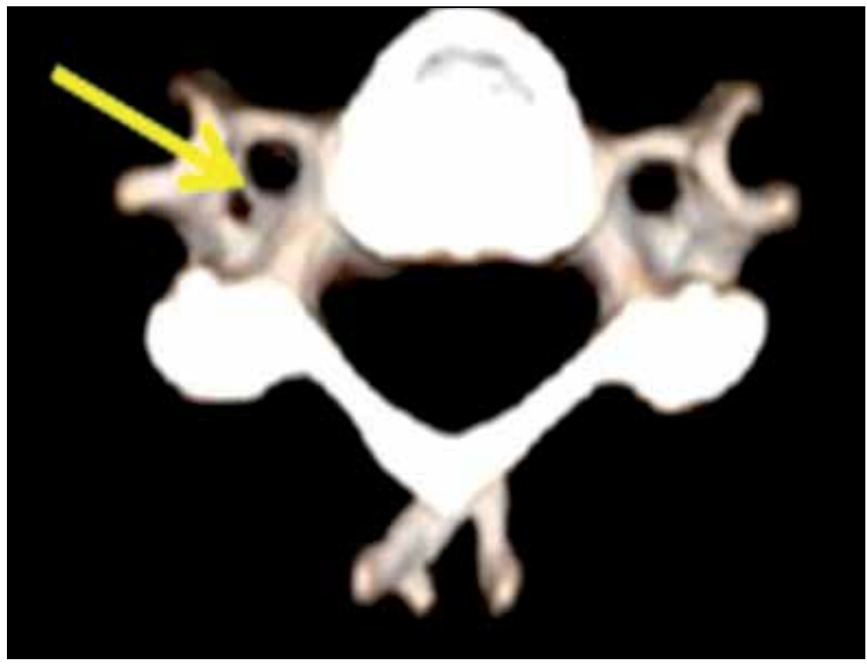

Figure 2: Complete double foramen at C5 level on the right side in 3D VR image.

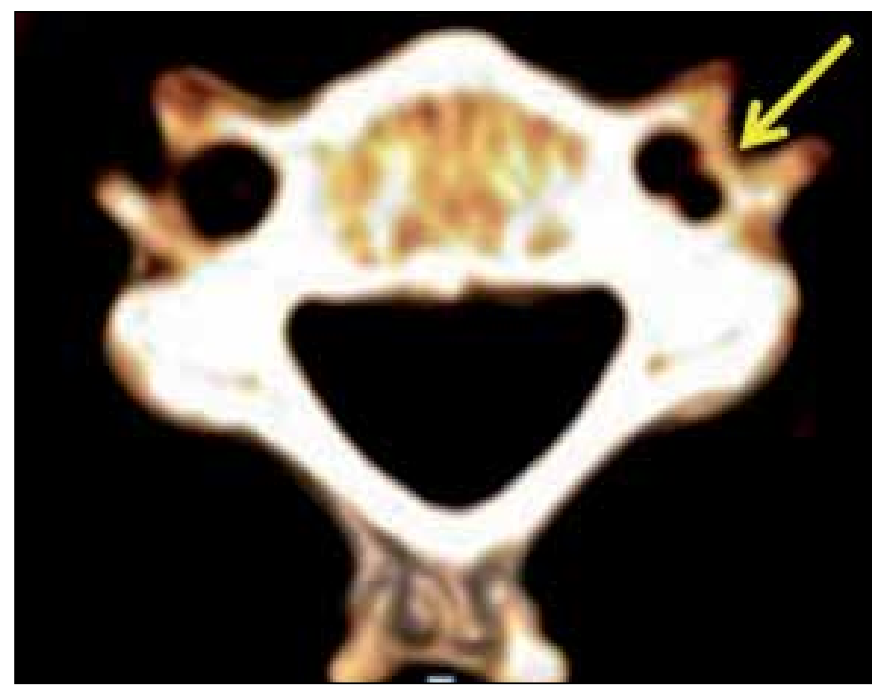

Figure 3: Incomplete double foramen at C5 level on the left side in 3D VR image. 


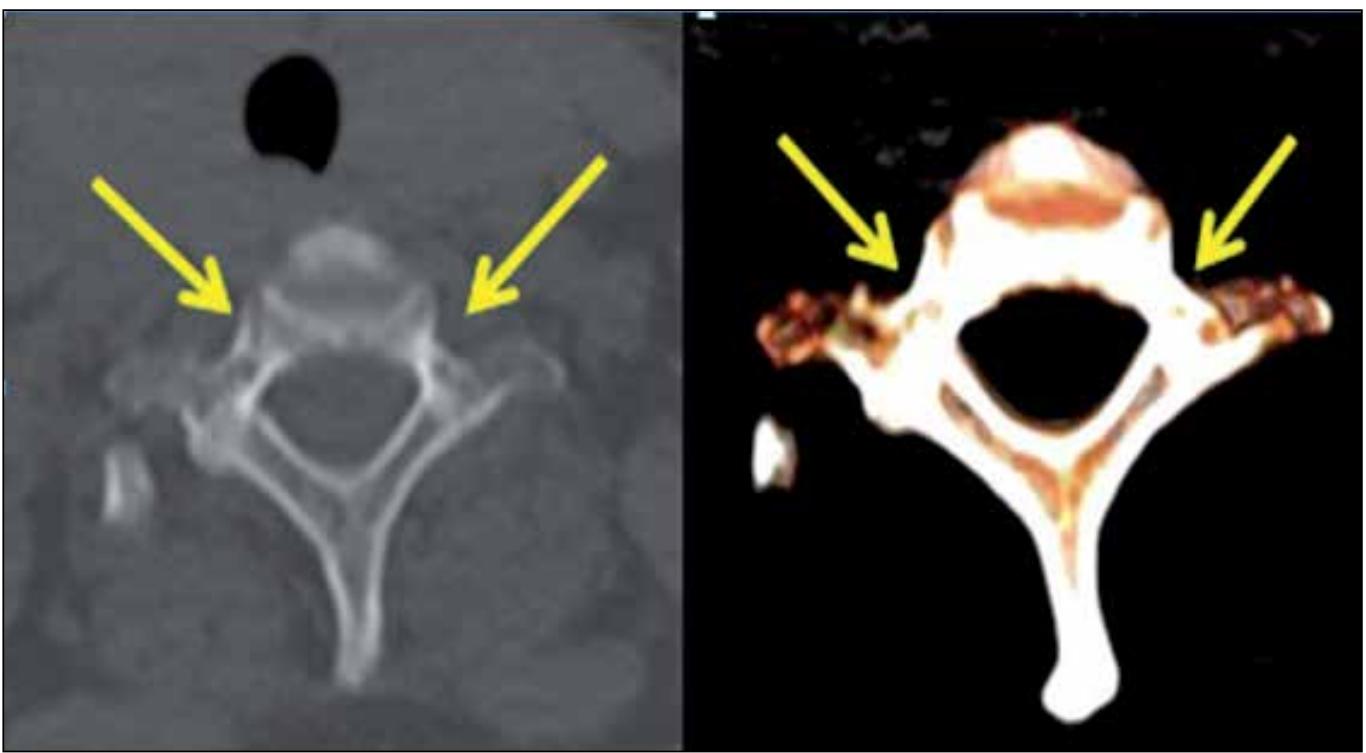

Figure 4: Bilateral

agenesis of TF at $\mathrm{C} 7$ level in axial and 3D VR image.

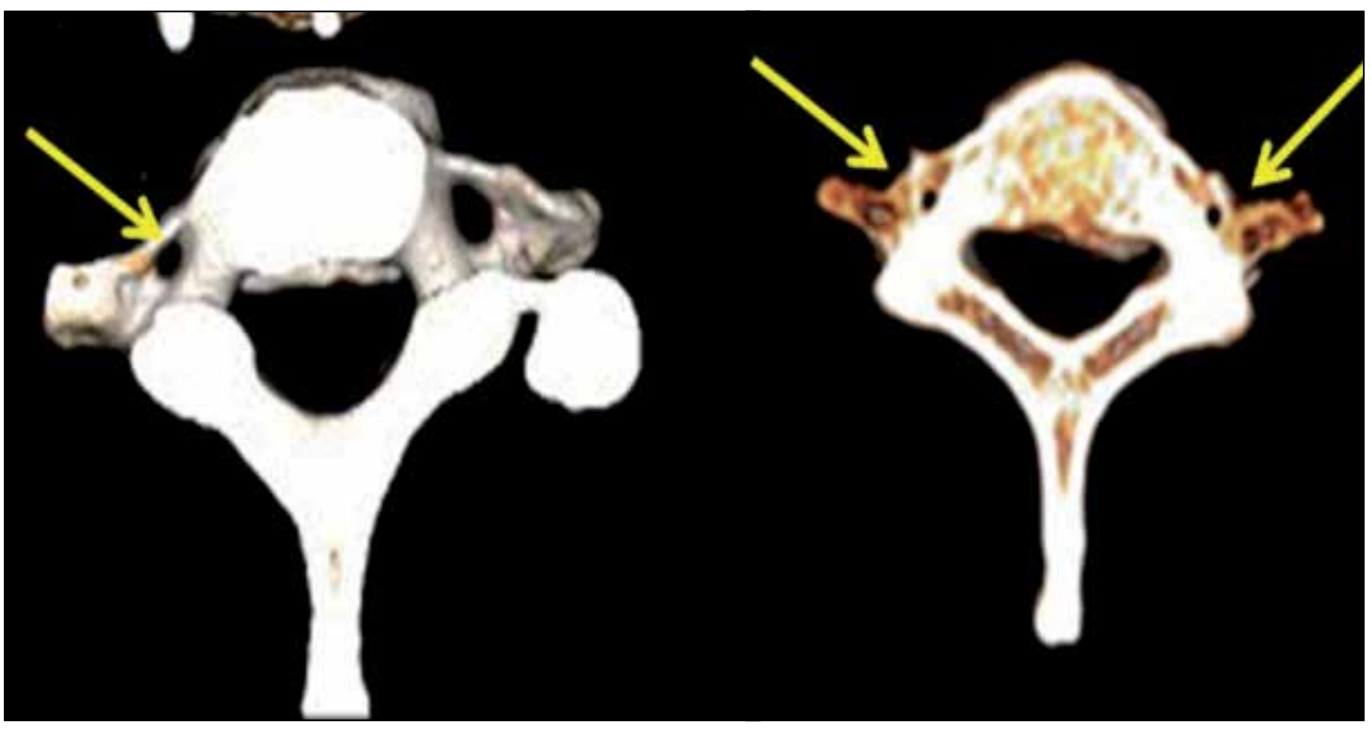

Figure 5: Hypoplasia at $\mathrm{C} 7$ level on the right side and bilateral side in MPR and 3D VR image.

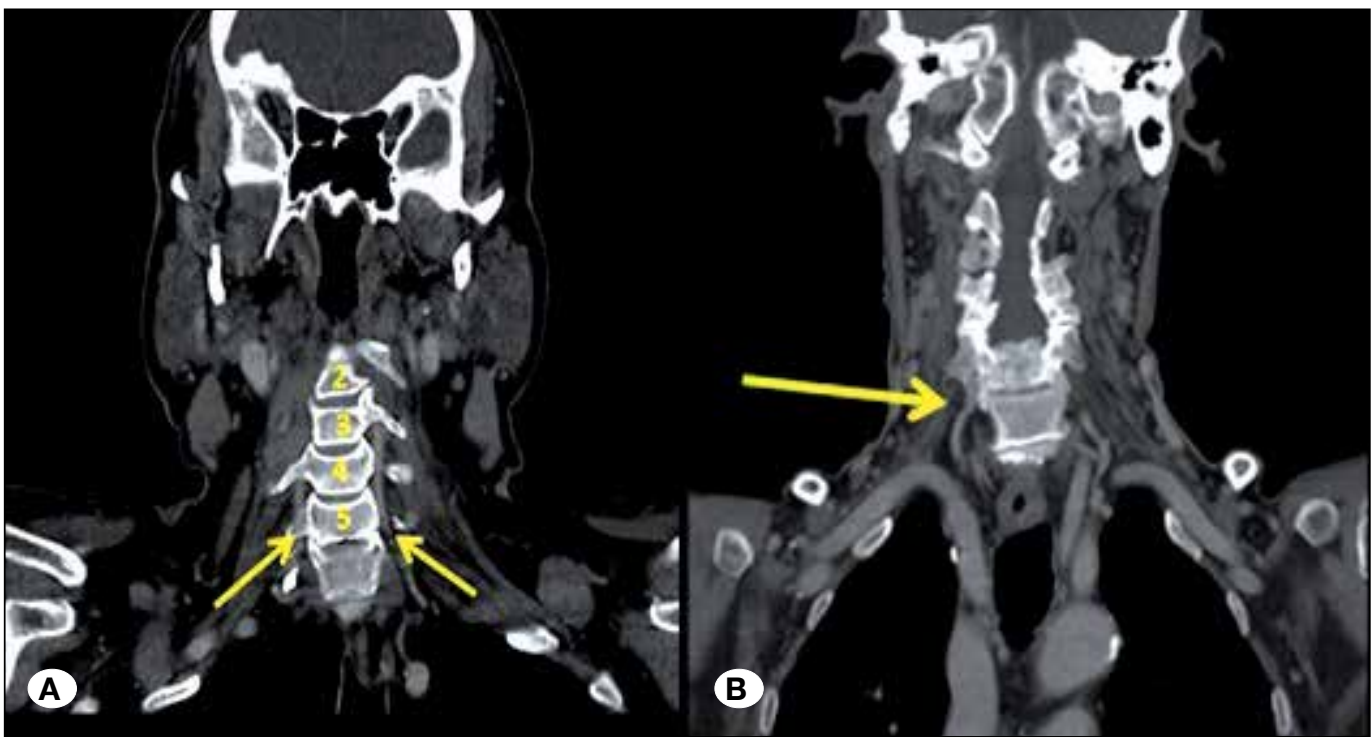

Figure 6: Coronal images show VA entry level at C5 vertebra (A) and at C6 level on the right side $(\mathbf{B})$. 
Table II: Variation Types and Their Levels and Numbers of Transverse Foramina

\begin{tabular}{|c|c|c|c|c|c|c|c|c|c|c|c|c|}
\hline \multirow[t]{2}{*}{ Vertebrae } & \multicolumn{3}{|c|}{ Agenesia } & \multicolumn{3}{|c|}{ Hypoplasia } & \multicolumn{3}{|c|}{$\begin{array}{c}\text { Complete double } \\
\text { foramen }\end{array}$} & \multicolumn{3}{|c|}{$\begin{array}{l}\text { Incomplete double } \\
\text { foramen }\end{array}$} \\
\hline & Right & Left & Bilaterally & Right & Left & Bilaterally & Right & Left & Bilaterally & Right & Left & Bilaterally \\
\hline \multicolumn{13}{|l|}{ C1 } \\
\hline $\mathrm{C} 2$ & & & & 1 & & & 1 & & & 1 & & \\
\hline $\mathrm{C} 4$ & & & & 1 & & & 3 & 1 & & 2 & 3 & 1 \\
\hline C5 & & & & & & & 8 & 9 & 4 & 15 & 9 & 7 \\
\hline $\mathrm{C6}$ & 1 & 2 & 1 & 1 & 2 & 4 & 7 & 5 & 3 & 12 & 8 & 3 \\
\hline Total & 19 & 18 & 15 & 13 & 12 & 4 & 21 & 15 & 7 & 31 & 21 & 11 \\
\hline
\end{tabular}

Table III: Variation of Vertebral Artery Entering into Cervical Transverse Foramina

\begin{tabular}{lcc}
\hline & Frequency & Percent (\%) \\
\hline C4 & 1 & 0.45 \\
\hline C5 & 4 & 1.84 \\
\hline C6 & 209 & 95.87 \\
\hline C7 & 4 & 1.84 \\
\hline Total & 218 & 100 \\
\hline
\end{tabular}

their medical reports. The level of the variations was detected through 3D images. We were also able to identify different variations such as agenesia and hypoplasia. Bilateral AP and $\mathrm{T}$ diameters of the TFs were measured from levels $\mathrm{C} 1-\mathrm{C} 7$. We observed that both diameters decreased from $\mathrm{C} 1$ to $\mathrm{C} 7$. There was no significant difference between the right and left in terms of diameters. In their study, Cagnie et al. identified that the left TF was wider than the right TF; they proposed a hypothesis that arteries on the left might be larger than those on the right (2). TF diameter is a good indicator of VA size; a small TF might indicate VA hypoplasia. Gupta et al. identified that the minimum diameter of TF was $1.50-2.00 \mathrm{~mm}$ wider than VA's internal diameter at the same level. The authors stated that $3.75 \%$ of TFs might have hypoplastic VTs (7). In their CT angiography studies, Kim et al. reported that there was a linear relationship between VA size and TF diameter (8). At the end of our study, we identified that a hypoplastic foramen was seen in $2.63 \%$ of patients. Agenesis was determined in 37 vertebrae (C6 and C7) with an incidence of $3.74 \%$. As in our study, Degirmenci and Yılmaz determined double TF as the most common variation in cervical vertebrae. Unlike our study, they reported the incidence of hypoplasia as more common (10.4\%) and agenesia as less common (4).

Determining the VA's level of entry through TFs increases the importance of this study. The most common entry level for VA through TF was C6 and the least common levels were C4, $\mathrm{C} 5$, and C7. Although our findings are similar to the study of Shin et al.(15), the most common entry level for VA was C3 in a study by Uchino et al., which was performed using CT angiography (16). In their cadaveric study, Jitendra et al. found that all VA entry levels were only at C6 and C7 levels. The small number of cases in cadaveric studies could be the reason for the lower incidence of variations (13).

\section{CONCLUSION}

With this study, we have provided detailed data on the anatomy of TF and VA entry. TF and VA are important anatomic structures for surgeons, specialists, radiologists, neurologists, and anatomists who study and work in this area. Knowledge about TF morphometry will significantly affect the success rates of physicians in the diagnosis and treatment of diseases associated with this region and benefit related surgical interventions by avoiding possible complications. Also, understanding the anatomic structures, and knowing that these structures might show variations on different scales will help anatomy education.

\section{REFERENCES}

1. Aggarwal B, Gupta $M$ : Variations of foramen transversarium in seventh cervical vertebra. International Journal of Basic and Applied Medical Sciences 4:258-262, 2014

2. Cagnie B, Barbaix E, Vinck E, D'Herde K, Cambier D: Extrinsic risk factors for compromised blood flow in the vertebral artery: Anatomical observations of the transverse foramina from C3 to C7. Surg Radiol Anat 27: 312-316, 2005

3. Chaudhari ML, Maheria PB, Bachuwar SP: Double foramen transversarium in cervical vertebra: Morphology and clinical importance. Int J Res Med 8:1084-1088, 2013

4. Degirmenci B, Yılmaz O: Variations of transverse foramens of cervical vertebrae: A 3-dimensional multidetector CT study. Turk J Med Sci 43:711-717, 2013

5. Drake RL, Vogl W, Mitchell AWM: Regional anatomy-skeletal structure. In: Yıldırım M (ed), Gray's Anatomy for Students. Istanbul: Gunes Bookstore, 2007: 30-32

6. Gray H: The Vertebral Column. Anatomy of the Human Body. Berlin: Bartleby Bookstore, 2001: 50-60 
7. Gupta R, Kapoor K, Kochhar S, Sharma A, Sahni D, Chawla $\mathrm{K}$ : Variations in morphometry of foramina transversaria and vertebral artery in subaxial cervical region and its surgical implications. IJHBR 3:47-54, 2014

8. Kim C, Lee SH, ParkSS, Kim BJ, Ryu WS, Kim CK, Oh MY, Chung JW, Yoon BW: A quantitative comparison of the vertebral artery and transverse foramen using CT angiography. J Clin Neurol 8:259-264, 2012

9. McMinn RMH: Head and neck and spine. In: McMinn RMH (ed), Last's Anatomy Regional and Applied. London: Elsevier Academic Press, 2011: 533-538

10. Moore KL, Agur AMR, Dalley A: Back. In: Moore KL (ed), Essential Clinical Anatomy. Baltimore, Wolters Kluwer Health, 2014: 278-282

11. Murlimanju BV, Prabhu LV, Shilpa K, Rai R, Dhananjaya KV, Jiji J: Accessory transverse foramina in the cervical spine: Incidence, embryological basis, morphology and surgical importance. Turk Neurosurg 21: 384-387, 2011
12. Rathnakar P, Remya K, Swathi: Study of accessory foramen transversaria in cervical vertebrae. NUJHS 3:97-99, 2013

13. Rawal JD, Jadav HR: Anatomical study of variation of vertebral artery entering the foramen transversarium of cervical vertebrae. National Journal of Medical Research 2: 199-201, 2012

14. Rekha BS, Dhanalaxmi DN: Variations in foramen transversarium of atlas vertebra: An osteological study in South Indians. NUJHS 2: 224-228, 2013

15. Shin HY, Park JK, Park SK, Jung GS, Choi YS: Variations in entrance of vertebral artery in Korean cervical spine: MDCTbased analysis. Korean J Pain 27: 266-270, 2014

16. Uchino A, Saito N, Takahashi N, Okada Y, Kozawa E, Nishi N, Mizukoshi W, Nakajima R, Watanabe Y: Variations in the origin of the vertebral artery and its level of entry into the transverse foramen diagnosed by CT angiography. Neuroradiology 55: 585-594, 2013

17. White TD, Black MT, Folkens PA: Human Osteology. California: Elsevier Academic Press, 2011:139 